\title{
Una mirada crítica sobre el patrimonio mundial de la UNESCO \\ JAIME JOVER BÁEZ
}

$>$ Doctor en Geografía. Investigador Posdoctoral, Department of Environmental Psychology, University of New York, Estados Unidos jjover@gc.cuny.edu

ORCID 0000-0002-1796-1655

Universidad de Valparaíso

Facultad de Arquitectura

Revista Márgenes

Espacio Arte Sociedad

Una mirada crítica sobre el patrimonio mundial de la UNESCO

Diciembre 2021 Vol $14 \mathrm{~N}^{\circ} 21$

Páginas 55 a 62

ISSN electrónico 0719-4436

Recepción marzo 2021

Aceptación julio 2021

DOI 10.22370/margenes.

2021.14.21.3095

\section{RESUMEN}

La Convención del Patrimonio Mundial de la UNESCO se firmó en 1972 y, desde entonces, ha evolucionado conforme lo ha hecho la disciplina patrimonial. A los tipos de patrimonio cultural que había que salvaguardar (monumentos, conjuntos y lugares) se han unido, por ejemplo, los paisajes culturales. También han aparecido otros acuerdos, como la Convención del Patrimonio Inmaterial de la Humanidad, que busca preservar tradiciones, costumbres y usos populares. Ahora bien, en el marco de la Convención del Patrimonio Mundial, existe un ámbito inalterado: los principios que marcan la salvaguardia del patrimonio y que los Estados han de cumplir. El artículo cuarto dice que son identificar, proteger, conservar, rehabilitar y transmitir a las generaciones futuras el patrimonio cultural, y han de tratarse en igualdad de condiciones. Esta presentación trata de reflexionar sobre la colisión de algunos de esos principios en la gestión de los sitios Patrimonio Mundial. A través del caso de la Catedral de Sevilla, se explora la privatización de un espacio que, al tiempo de la declaratoria, era público, y cómo este cambio altera la difusión de sus valores culturales. El caso de la Mezquita de Córdoba obliga a pensar sobre qué se identifica como patrimonio, y cómo afectan los diferentes usos en un monumento. El caso de la Ciudad Mercantil de Liverpool ilustra cómo los nuevos desarrollos urbanísticos alteran la conservación y amenazan con perder el estatus de Patrimonio Mundial. Las reflexiones pretenden profundizar en la articulación entre la Convención y las herramientas estatales de protección a la par que provocar una discusión sobre la efectiva salvaguardia de los principios que estructuran la defensa del patrimonio según la UNESCO.

\section{PALABRAS CLAVE}

teoría del patrimonio, consumo del patrimonio, Patrimonio Mundial, UNESCO

\section{A critical insight into UNESCO world heritage} ABSTRACT

The UNESCO World Heritage Convention was signed in 1972 and has evolved since then alongside the heritage discipline. For example, cultural landscapes have joined the original heritage categories: monuments, groups of buildings, and sites. The Convention for the Safeguarding of the Intangible Cultural Heritage appeared in 2003 to preserve traditions, customs, or social practices. However, within the framework of the World Heritage Convention, there is an unaltered matter: the principles to safeguard heritage that States must enforce. The fourth article states these are the identification, protection, conservation, presentation and transmission to future generations of the cultural and natural heritage, which must be understood on equal terms. This presentation reflects upon the collision of some of these principles with the management of World Heritage sites. Through the case of the Cathedral of Seville, we explore how heritage privatization alters the 
diffusion of its cultural values. The conflict around the Mosque of Córdoba makes us think about what is identified as heritage and how it affects the different monument uses. The Mercantile City of Liverpool illustrates how new urban development disrupts conservation and threatens World Heritage status. The reflections seek to deepen the articulation between the Convention and state protection tools while stimulating debates on the efficient safeguarding of the principles that structure UNESCO's World Heritage.

\section{KEYWORDS}

heritage theory, heritage consumption, World Heritage, UNESCO

\section{PRESENTACIÓN}

Para esta presentación, sobre diálogos de patrimonio, y sobre el patrimonio como bien de consumo, empecé a pensar mucho en los distintos estudios de casos que he ido trabajando en los últimos años que son fundamentalmente en Sevilla y en Córdoba, 2 ciudades andaluzas de modelo mediterráneo, con centros históricos clásicos, con una expansión urbana muy fuerte a partir de los años 50' y sobre todo 60' y 70', pero que conservaron muy bien monumentos y parte del patrimonio urbano en general, con bastante transformación. Son ciudades similares, aunque Sevilla es significativamente más grande que Córdoba. Y el caso de Liverpool también, que es una ciudad a la que estoy vinculado hace tiempo, y he venido investigando algo allá. Al final lo que tienen en común estas ciudades es el Patrimonio Mundial de la UNESCO, y como se ha venido usando ese Patrimonio Mundial para convertir la ciudad en recurso turístico, a pesar de que de ese uso ha derivado en una serie de contradicciones en algún momento.

En fin, son una serie de reflexiones les quería advertir, que no tienen así una gran coherencia entre sí. Hay un hilo conductor que es de la Convención del Patrimonio Mundial, pero en general voy a plantear más preguntas que respuestas. Voy a plantear, voy a hablar del patrimonio en conflicto, voy a hablar de la condición de Patrimonio Mundial evidentemente, que, seguro que todos ustedes más o menos conocen, y voy a hablar de los estudios de caso que he comentado.

Bueno, el patrimonio en conflicto, patrimonio en contradicción, no me gusta hacer mucha dicotomía en general, pero por razones analíticas esta suele funcionar bastante bien. Existe una doble dicotomía del patrimonio como bien cultural y como bien de consumo, yo lo asocio a la modernidad y a la postmodernidad. Es decir, seguramente puesto que todos ustedes que estudian un Magíster en Patrimonio ya saben del tema, en algún momento habrán estudiado la creación del patrimonio como elemento legitimador del Estado en el siglo XIX con todas sus contradicciones a lo largo de los años, especialmente en los últimos tiempos, en el contexto democrático, y también conocerán un poco la forma en la cual se generan discursos autorizados del patrimonio, como hay distintos trabajos sobre cómo las élites han utilizado el patrimonio histórico para legitimarse en el poder, como una forma de control social. Y dentro de esos contextos más institucionales se han creado una serie de dicotomías como la del patrimonio cultural frente al natural, o también el patrimonio material contrapuesto al inmaterial. Y eso entra en juego con la propia teoría del patrimonio, que está muy trabajado por las escuelas de antropología, esto es, el patrimonio como una relación social que se genera en la comunidad, un grupo de personas en un espacio geográfico más o menos determinado que entiende una serie de elementos materiales e inmateriales parte de su pasado común y los mantienen vivos por el mero hecho de mantener unas ciertas tradiciones o incluso lo quieren preservar por ser parte de su identidad, parte de su razón de ser como colectivo, y eso es su patrimonio. Así se presentaría otra suerte de dicotomía entre un patrimonio más institucional, y un patrimonio más comunitario o social.

Voy a poner un ejemplo. Cuando un estado, en el caso de España, las Comunidades Autónomas que tienen las competencias sobre patrimonio, quieren preservar un elemento que consideren como patrimonio o bien cultural, es porque hay una colectividad que lo entiende así. Pueden darse casos que no sucedan así, pero lo normal es que la acción política y administrativa satisfaga la necesidad social, de la sociedad a la que sirve esa institución. Todo esto se relaciona con la teoría de los bienes culturales, que es importante, porque sin ella no se entiende la Convención del Patrimonio Mundial, que se firma en 1972. La teoría de los bienes culturales surge en la Italia de los años 60 a través de la comisión Franceschini, que dice esencialmente que las cosas tienen un derecho de propiedad, pertenecen a alguien, a una institución o a una persona, pero evidentemente si son patrimonio tienen un interés público, un interés general, y eso hace que estén tuteladas por los poderes públicos.

Eso sería un resumen del contexto del nacimiento del patrimonio en el contexto moderno. Lo moderno es un concepto un poco complicado, porque, ¿qué es la modernidad? Claro, no vamos a entrar en eso, pero bueno, lo que quiero decir es que el punto de llegada del patrimonio en el siglo XX es el Patrimonio Mundial, y esa convención se firma en un contexto geopolítico global, a la que sucede lo post moderno en términos culturales, post industrial en términos económicos con una fuerte desindustrialización y reconversión económica general, con un aumento del turismo global sin precedentes. Ese contexto que se genera en el último cuarto del siglo XX es lo que hace que se hayan movido un poco los cimientos 
de la Convención del Patrimonio Mundial, y para mí, se observa en los casos que vamos a ver. Y se mueve porque, al final, y desde una perspectiva Marxista, el valor de cambio de estos elementos patrimoniales está por encima del valor de uso, entendiendo el valor del uso en el patrimonio como su uso cultural por la sociedad, por lo que se configura un destino público de los bienes culturales.

Esta situación se impone en el contexto concreto del patrimonio, por el tema de la diferenciación de los territorios, que se plasma en estrategias concretas: en el caso de las ciudades, intentan cada vez más diferenciarse de otras para atraer el mayor número de capitales y/o de turismo posible y así, en el contexto de competición global, generar más recursos para la propia ciudad. Otra cosa sería preguntarse cómo se distribuyen esos recursos, pero ahí nos saldríamos un poco del objetivo marcado.

\section{¿QUÉ ES EL PATRIMONIO MUNDIAL?}

El Patrimonio Mundial como seguramente sabrán, en la convención del año 1972 dentro de la UNESCO, crea una serie de organizaciones: el Comité del Patrimonio Mundial, el Centro del Patrimonio Mundial, etcétera. Esas organizaciones van mejorando con el tiempo, y aparecen otras. También se crean los criterios de conservación y las categorías, que van evolucionando, igual que la Lista del Patrimonio Mundial, donde cada año entran más elementos. Todo esto lo articula la Convención junto con otros documentos anexos que la complementan y desarrollan, como las Operative Guidelines. La Lista del patrimonio mundial, para mí, es un club de elite en el cual aquellos elementos patrimoniales y bienes culturales de los estados que se consideran con un valor por encima de lo normal, universal, a escala mundial, pueden estar.

A pesar de todo no hay una legislación del patrimonio mundial, es un convenio internacional al que se suscriben los estados, y los estados normalmente hacen suyas algunas de las ideas del Patrimonio Mundial; por ejemplo, las categorías originales son los conjuntos, que se traducen en los centros históricos, las zonas típicas, las sitios antropológicos, etcétera. Y al mismo tiempo, la Convención establece una serie de criterios que se basan en la integridad y la autenticidad, que se concibe como valor universal, que en concreto en el Patrimonio Mundial de corte cultural son seis, son valores en los que no quiero entrar en detalle, pero dan sentido a la declaración, por ejemplo, que una obra sea única en el mundo porque haya influido en otros estilos, en otras épocas, en este tipo de cosas. Estos valores se fundamentan en unos principios, que son en los que se basa la letra pequeña de cada bien cultural, una serie de normas sobre cómo se rige y como se protege el patrimonio, que normalmente se incluyen en los documentos que acompañan a las declaratorias y en los planes de gestión posteriores.

También cabe decir que el Patrimonio Mundial ha ido evolucionando, hoy existen nuevas categorías, hay Patrimonio Mundial cultural y natural mixto, están los paisajes culturales que se incluyeron en 1992, hay una nueva Convención del Patrimonio Inmaterial de la Humanidad, que ese es en realidad el patrimonio de la humanidad. Cuando en prensa o comúnmente se suele hablar del Patrimonio de la Humanidad, muchas veces se refiere al Patrimonio Mundial. En realidad, el Patrimonio de la Humanidad es el inmaterial, y el Patrimonio Mundial es el material, aunque yo no sea muy fan de estas categorías, porque no son absolutas.

El tema de los principios es muy importante, y es en lo que me quiero centrar: los estados se comprometen a identificar, proteger, conservar, rehabilitar y transmitir a las generaciones futuras cada uno de los bienes que ellos tutelan en la Lista del Patrimonio Mundial. Eso es fundamental porque son 5 principios que se deben entender interrelacionados entre sí, sin jerarquía ninguna, y que deberían implementarse al mismo tiempo en cada uno de los bienes que se van a conservar, quizás de distinta forma, porque cada uno de los bienes es diferente. No es lo mismo cómo se gestionan esos principios en el caso de los monumentos, donde estamos hablando del patrimonio arquitectónico, que en el caso de otro tipo de bienes como los que pertenecen al patrimonio urbano o arqueológico. El problema es que no todos los principios se observan al mismo nivel, y aquí es donde entra la sumisión del valor de cambio sobre el de uso, o el consumo del patrimonio a grandes rasgos. La UNESCO también garantiza que los estados reciban asistencia técnica y financiera, cuando haga falta; hay un punto de vista redistributivo, porque la situación de todos los estados en el mundo no es la misma.

Entonces, habiendo establecido esto, voy a entrar a explicar los estudios de caso.

\section{REVISIÓN DE CASOS}

\section{Sevilla}

Del primero que voy a hablar es de Sevilla, en concreto de su Patrimonio Mundial: son 3 bienes, el Archivo de Indias, el Alcázar y la Catedral, junto con su campanario: la Giralda. Estos tres bienes estuvieron cerca de entrar en una lista complementaria a la del Patrimonio Mundial, la lista del Patrimonio Mundial en peligro. Como el nombre indica, aquí están los bienes que la UNESCO entiende que no se están conservando conforme a los criterios que se habían establecido en su declaratoria. En el caso de Sevilla ha estado a punto de entrar en esa lista por este edificio, la Torre Pelli, un rascacielos de 178 metros de altura de reciente construcción. Y aunque no voy a hablar de esto en concreto, siempre me parece interesante introducir estos temas, porque los debates en torno al Patrimonio Mundial son muchos.

En concreto en Sevilla me interesa hablar de uno de los espacios que se declara como Patrimonio Mundial en el año 1987. Estamos ante la Catedral gótica mayor de España, una de las más grandes del mundo, que está gestionado por la Diócesis de Sevilla. En la declaratoria se habla de distintas fases de construcción, y de distintos elementos, como la capilla mayor, la Giralda, o el patio de los Naranjos. Es sobre este último en el que me quiero centrar. Antes debo decir que la Catedral es Monumento Nacional, hoy llamado bien de interés cultural, desde el año 1929, y a lo largo del tiempo ha recibido hordas de inversión para rehabilitaciones por parte del estado. En concreto, sobre el patio de los Naranjos, en la declaración de la UNESCO se establece que el espacio es un elemento fundamental en la confección del edificio, es uno de los pocos testigos que quedan de la mezquita aljama original, que se refiere a otra época histórica, a otro momento en la península Ibérica, y a otro contexto socio-político muy diferente. Además, se habla de que es un espacio clave para interpretar el resto del edificio. ¿Y qué es lo que ha ocurrido? Pues ha habido una privatización, en 1992, cinco años después de la declaración por la UNESCO, cuando la Diócesis de Sevilla cierra el patio de los Naranjos al público. ¿Por qué lo cierra? Pues la decisión está en la onda de la transformación de la Catedral en un bien de consumo. 

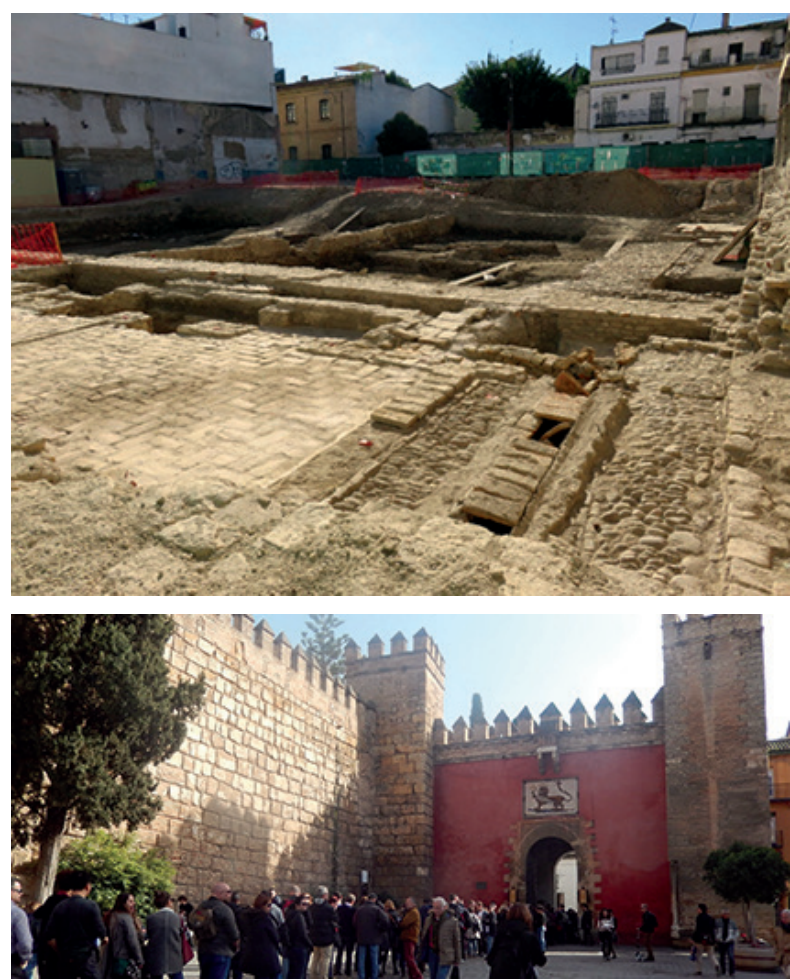

$>$ Figura 1. Excavaciones en la ciudad de Sevilla tras el derribo de unos antiguos talleres y almacenes, España. Fuente: Fotografía del autor.

Figura 2. Alcázar de Sevilla. Día de visitas. Fuente: Foto del autor.
El año 92 no fue un año cualquiera en Sevilla, es el año de la Exposición Universal que reconfigura la estructura urbana de la ciudad casi por completo, y empezó a llegar mucho turismo, especialmente turismo internacional, una tendencia que ya por entonces se veía que continuaría, como así ha ocurrido. El patio de los Naranjos se cierra entonces con la excusa de una exposición, y nunca se vuelve a abrir al público. De un espacio público, una plaza pública donde los niños jugaban, de espacio de recreo propio de la ciudad, que además en el centro histórico tiene muy pocos espacios públicos, se convierte en un espacio privado-turístico, o sea, cuando te venden la entrada a la Catedral, la última experiencia de la visita es el patio de los Naranjos, lo que es un poco incomprensible. Digo esto porque salir del templo por el patio de los Naranjos es un poco extraño siendo la puerta histórica del edificio, la entrada al patio de las abluciones cuando era mezquita. Lo que quiero decir es que, con esta privatización de un espacio UNESCO, se han alterado los principios para comprender el edificio, especialmente el que habla de la difusión, la transmisión a generaciones futuras del patrimonio. De hecho, hay un movimiento ciudadano muy importante en Sevilla que quiere recuperar ese espacio como plaza pública.

\section{La mezquita de Córdoba}

Oficialmente, el nombre es Mezquita-Catedral, aunque prefiero usar el nombre de mezquita que es como se la conoce popularmente. En este caso el conflicto es otro, la atención se centra sobre el significado del Patrimonio Mundial en tanto que lo que está ocurriendo con el edificio afecta a la declaratoria de la UNESCO.

La mezquita de Córdoba es uno de los edificios más antiguos de la península Ibérica, y por ende de los más antiguos de Europa. Se comenzó a construir en el siglo VIII y a lo largo de los siglos ha tenido diferentes ampliaciones e intervenciones, sobre todo durante los 500 años en que es la mezquita mayor de la ciudad del estado musulmán de la península lbérica, con distintas etapas a su vez, el Emirato primero, o el Califato de Córdoba después, el momento de mayor esplendor. El edificio pasa por derecho de conquista a la Corona de Castilla en el siglo XIII, en plena Edad Media. El derecho de conquista es importante porque se entiende que se le arrebatan al estado musulmán por la acción de la Corona castellana, es decir, que pertenecen al rey por la conquista, y es el rey quien se los cede a la Iglesia Católica. Esto es muy importante, y de hecho hasta hace muy pocos años, la Iglesia, la Diócesis de Córdoba en concreto, no tenía un papel donde se establecía la propiedad del edificio. Ahora hay una controversia sobre la propiedad, de quien es la mezquita de Córdoba, porque la Diócesis, utilizando una norma franquista, se apropia de ella en 2006, consigue un papel de titularidad, lo que puede ser un tanto contradictorio con el destino público de los bienes culturales que hablábamos antes. Además, cabe destacar que en el siglo XVI hubo mucha polémica con la mayor intervención sobre el edificio: fue el emperador Carlos $V$ quien permite que se construya una apertura sobre el arte islámico de la mezquita. La nave que se construye es de un estilo renacentista, y que hace que el edificio tenga ese carácter ecuménico, con distintas etapas arquitectónicas que son muy interesantes, que la convierten en un bien único.

La mezquita de Córdoba es patrimonio nacional desde 1882, de los primeros de España, y es Patrimonio Mundial desde 1984. En la declaración del Patrimonio Mundial se habla de esto, de las distintas fases, distintas etapas que representan muy bien la historia de la península Ibérica, pero fundamentalmente se habla del va- 
lor principal de la mezquita es su carácter como edificio simbólico principal de la arquitectura religiosa, del islam en Occidente, no hay otro igual, no hay otro mayor, que además influye en otros estilos y épocas. Evidentemente, la nave renacentista tiene su valor increíble y no lo vamos a negar, pero el arte musulmán está ahí, de hecho, hay una anécdota que recogen distintos historiadores, de que cuando Carlos V, después de haber aprobado la obra, llega a Córdoba años después y le dice al obispo que bueno, algo así como ha construido en Córdoba lo que ya existe en otros sitios, y ha destruido lo que no existe en ninguna parte, refiriéndose a la parte de la mezquita que había destruido. ¿Y por qué hablamos del significado al final? La cuestión es que la Diócesis de Córdoba lleva unos 20 años diciendo que no es arte musulmán o islámico, sino que se trata de arte bizantino, o hablando de que antes de que existiera una mezquita, había una basílica cristiana de época visigoda, de lo que no hay datos historiográficos certeros.

Por ejemplo, aquí está el obispo de Córdoba en una entrevista afirmando que los moros solo pusieron el dinero. Todo este discurso se basa en una estrategia de hablar de la Catedral de Córdoba en lugar de la mezquita de Córdoba, y así hablar de la intervención islámica del edificio como en unos panfletos que estuvieron en circulación durante unos años. En fin, se está intentando obviar o eliminar el pasado musulmán, y privilegiar otro tipo de pasados, lo que al final tiene sentido dentro del objetivo de la Iglesia Católica, siendo uno de ellos la evangelización, pero claro, aquí comentamos que se está gestionando un elemento que es patrimonio de Córdoba, de Andalucía, de España, y del globo entero como Patrimonio Mundial, lo que transciende a los objetivos de la Iglesia. Se está intentando cambiar un significado a un edificio, que además es uno de los elementos turísticos principales de la ciudad y de Andalucía, es un bien de consumo fundamental porque el $98 \%$ de los turistas que van a Córdoba pasan por la mezquita, y si no estoy equivocado es el tercer edificio más visitado de España, creo que el primero es la Alhambra en Granada, luego está la Sagrada Familia de Barcelona, y luego está la Mezquita de Córdoba. Además, se da que hay mucho turista que es musulmán, y por eso ha aumento la seguridad privada dentro del edificio, buscando evitar que esos turistas recen silenciosamente en el templo. Llama mucho la atención el despliegue de fuerza privada que existe en un bien cultural como este.

\section{Ciudad Mercantil de Liverpool}

Y de aquí salto al último caso, al último estudio del que voy a hablar, que es la Ciudad Mercantil de Liverpool, que es muy diferente a los otros, pero hay un punto de comparación y ahora lo vamos a ver. El puerto de Liverpool es posiblemente el puerto más importante de la historia del siglo XIX, es sin duda el puerto más importante del Reino Unido en este período. El puerto de Liverpool es una infraestructura enorme que tiene muelles, almacenes, fábricas, zonas comerciales anexas que florecen con la Revolución Industrial, por el propio puerto, por la cercanía a Manchester también, y se convierte en uno de los nodos principales del comercio con las colonias británicas, con Estados Unidos, y con el resto del mundo en el siglo XIX, y se mantiene así a lo largo del XX, hasta aproximadamente los años 50,60, y sobre todo los 70, con la desindustrialización en el Reino Unido, cuando pierde mucha capacidad e importancia. La caída se prolonga durante los años 80, y hasta los años 90, donde hay un estado de abandono total, e incluso degradación en muchas zonas portuarias.
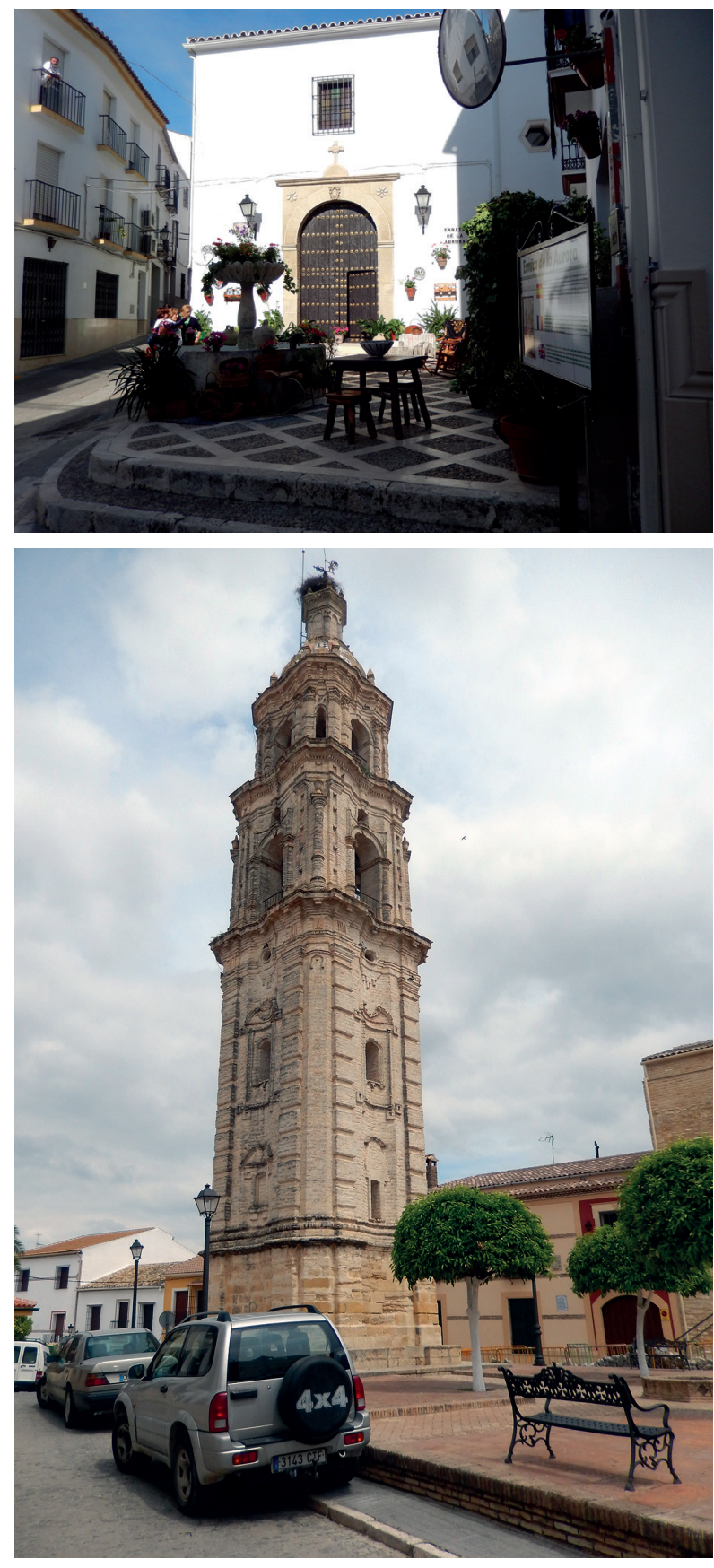

$>$ Figura 3. Eremita de la Aurora en Luque, Córdoba. Fuente: Fotografía del autor.

$>$ Figura 4. Torre del Reloj en Aguilar de la Frontera, Córdoba. Fuente: Fotografía del autor. 


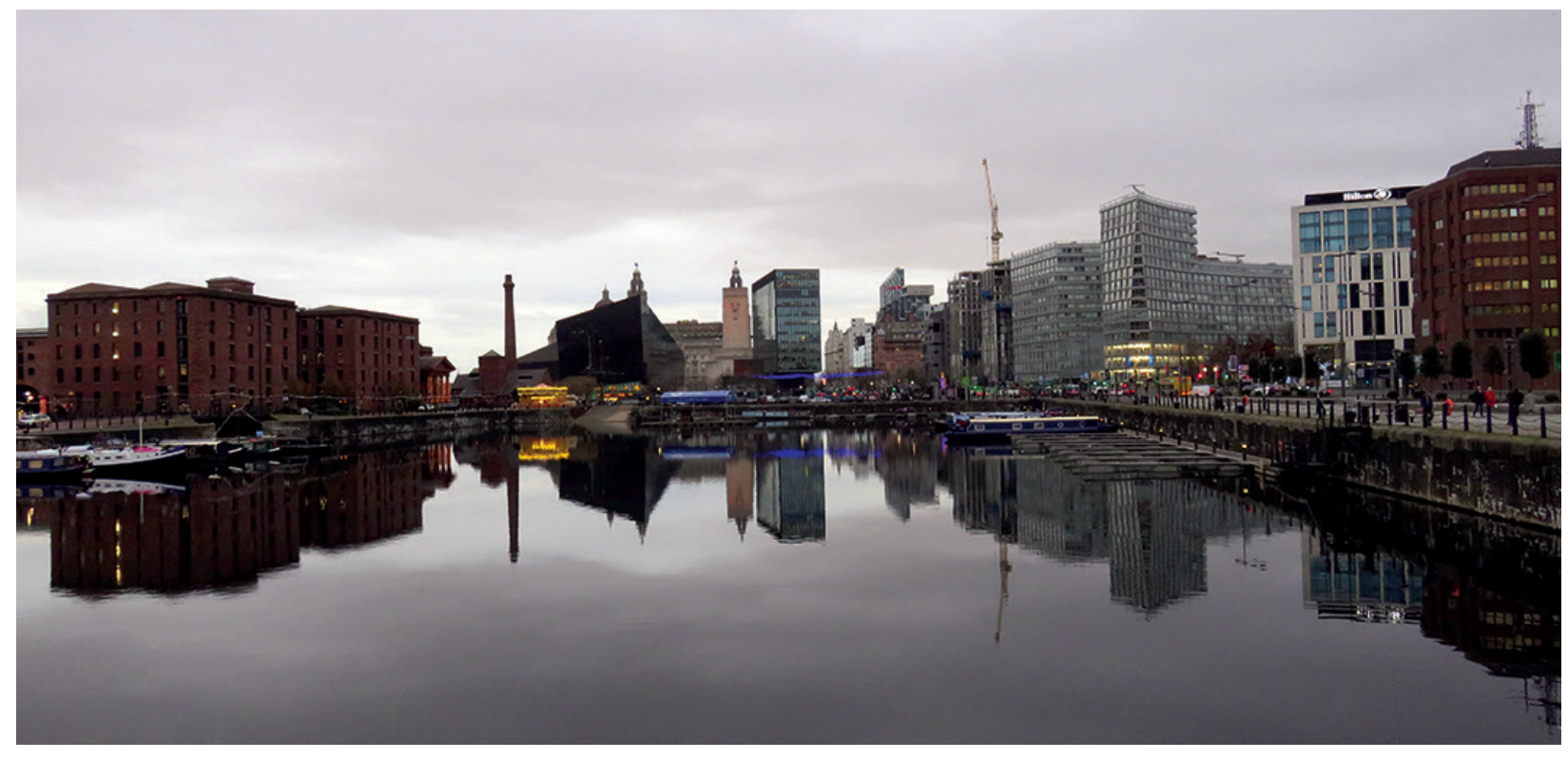

Por su parte, el centro urbano es muy típico de ciudades anglosajonas, un downtown clásico, por así decirlo, centros urbanos más comerciales que residenciales, y lo que se observa ya a principios de los 80 en ese abandono absoluto, y sobre todo a partir de los finales de los 90 , y se ha observado en otras ciudades anglosajonas, es un proceso de gentrificación muy importante, primero centrado en algunas zonas del centro y aledañas, donde se convierten muchas fábricas en edificios residenciales que luego van saltando hacia el puerto. Estas estrategias se complementan, sobre todo en el caso del puerto, con una estrategia turística de recuperación de espacios obsoletos, y ahí entra la declaratoria del Patrimonio Mundial del año 2004, que se venía gestando desde finales de Ios 90. El objetivo final es convertir a Liverpool en una ciudad puntera en el contexto de competición global a través de la cultura y especialmente el turismo, siendo la principal urbe en el norte de Inglaterra en este sentido, compitiendo con Edimburgo, en Escocia. Lo que ocurre poco después de la declaratoria es que hay un cambio en la alcaldía de la ciudad, del mismo signo político, pero entra otro alcalde que tiene otra visión, y la visión que él tiene en lugar de centrarse tanto en la cultura, es que es sí, es necesario atraer a turistas, pero también vamos a captar capitales extranjeros, en concreto a través del desarrollo inmobiliario. Aquí este ejemplo que he puesto al principio de Sevilla con la Torre Pelli sería un paralelismo, aunque se queda pequeño. El objetivo de este alcalde era construir todo un distrito financiero y residencial, y, ¿dónde lo quiere construir? Efectivamente, en la zona del puerto, que por eso entra en la lista del Patrimonio Mundial en peligro en el año 2012, donde todavía se encuentra.

El proyecto principal es de una empresa llamada Peel, que quiere construir una serie de edificios, muchas torres, algunas con capital chino, que van asociadas a otra red de servicios en esta zona. El motivo último se muestra en este plano de Liverpool que creo que es significativo. Liverpool es una ciudad muy dividida socialmente, el sur de la ciudad ha sido tradicionalmente una zona de clase media alta, mientras que el norte, donde están los famosos barrios de Anfield o Everton, vinculados a la cultura del fútbol o a los Beatles, es de clase trabajadora, cercana a las fábricas y al puerto y por tanto muy golpeada por la desindustrialización. Toda esa zona que abarcaba el centro urbano es la que se intenta revitalizar desde los 90, y así hay una frontera de la gentrificación

$>$ Figura 5. Ciudad Mercantil de Liverpool, UK. Fuente: Fotografía del autor. 
que avanza desde el sur hacia el norte a lo largo del waterfront, del antiguo puerto, donde se han construido una serie de edificios simbólicos y residencias muy importantes, que ahora se expanden hacia el norte. La situación actual es que, después de 8 años en la lista del Patrimonio Mundial en peligro, la UNESCO ha conseguido hacer un poco de contrapeso en cierto sentido y ha parado parte de este proyecto, pero Peel junto con la ciudad, que está muy convencida de que esto tiene que salir adelante, ha rehecho el proyecto, se han redistribuido las densidades y se va a hacer otro tipo de ciudad. Sigue habiendo temas controvertidos, ya no es la altura de las construcciones por ejemplo, sino como se están tratando los muelles históricos, qué se está haciendo con ellos. Por ejemplo, ahora hay un proyecto nuevo de campo fútbol para el Everton en uno de los muelles históricos que se rellena de tierra y se construye el campo encima, lo que es muy controvertido. Por no enrollarme, solo decir que intuyo que todo esto va a terminar seguramente con Liverpool, la Ciudad Mercantil, perdiendo su condición de Patrimonio Mundial, lo que no deja de ser contradictorio porque los desarrollos que se están haciendo ahora mismo hablan de las ventajas del patrimonio de la ciudad. Vayan a las páginas web de estas empresas que están construyendo y verán cómo algunas usan el Patrimonio Mundial como un elemento de atracción, ya no solamente para construir, sino para vender, es un bien de consumo fundamental, que al mismo tiempo está provocando que Liverpool pierda esa condición de Patrimonio Mundial.

\section{REFLEXIONES FINALES}

¿Qué es lo que ocurre con estos casos tan diversos? Pues, en mi visión, es que se está perdiendo un poco la intención de la Convención del Patrimonio Mundial porque se ha convertido en un sello de calidad turística. Y mientras tanto la UNESCO parece un poco autista o ausente, no sé cómo decirlo, porque no termina de reconocer que su sello de calidad ya no es tanto patrimonial, sino turístico o incluso inmobiliario, con todo lo que eso conlleva para la propia contextualización de patrimonio, para lo que entendemos como patrimonio, ya no solamente para los bienes en concreto. Al mismo tiempo, existe una doble explotación sobre el patrimonio, que es directa en tanto que bien de consumo, esto es, es una explosión económica, y también es indirecta en relación a las relaciones sociales y laborales que se generan alrededor, por ejemplo, en el ámbito del sector turístico. Es decir, si por lo menos esa explotación económica se destinará a distribuir los recursos de forma equitativa por parte del estado, no se justificaría en sí misma la explotación, pero se podría comprender desde una perspectiva productivista. Pero la realidad es que las personas que trabajan en aspectos patrimoniales, desde las que están en un museo, a las que están en las oficinas turísticas, hasta las de los servicios que dependen del turismo, normalmente son personales con un salario muy bajo en comparación con todo el dinero que el Patrimonio Mundial está moviendo en la economía real y en la financiera.

Al final lo que se observa es que los principios de la Convención no se encuentran al mismo nivel. En la teoría deberían estar interrelacionados y deberían ser considerados de forma equitativa, pero esto no es así. La protección y la rehabilitación del Patrimonio Mundial son muy importantes, son clave, la identificación y obviamente la conservación también, mientras que la transmisión a las generaciones futuras se entiende como la transmisión al visitante, a aquel individuo que tenga y traiga el dinero, al turista, en definitiva. Esto provoca al fin y al cabo que el Patrimonio Mundial se
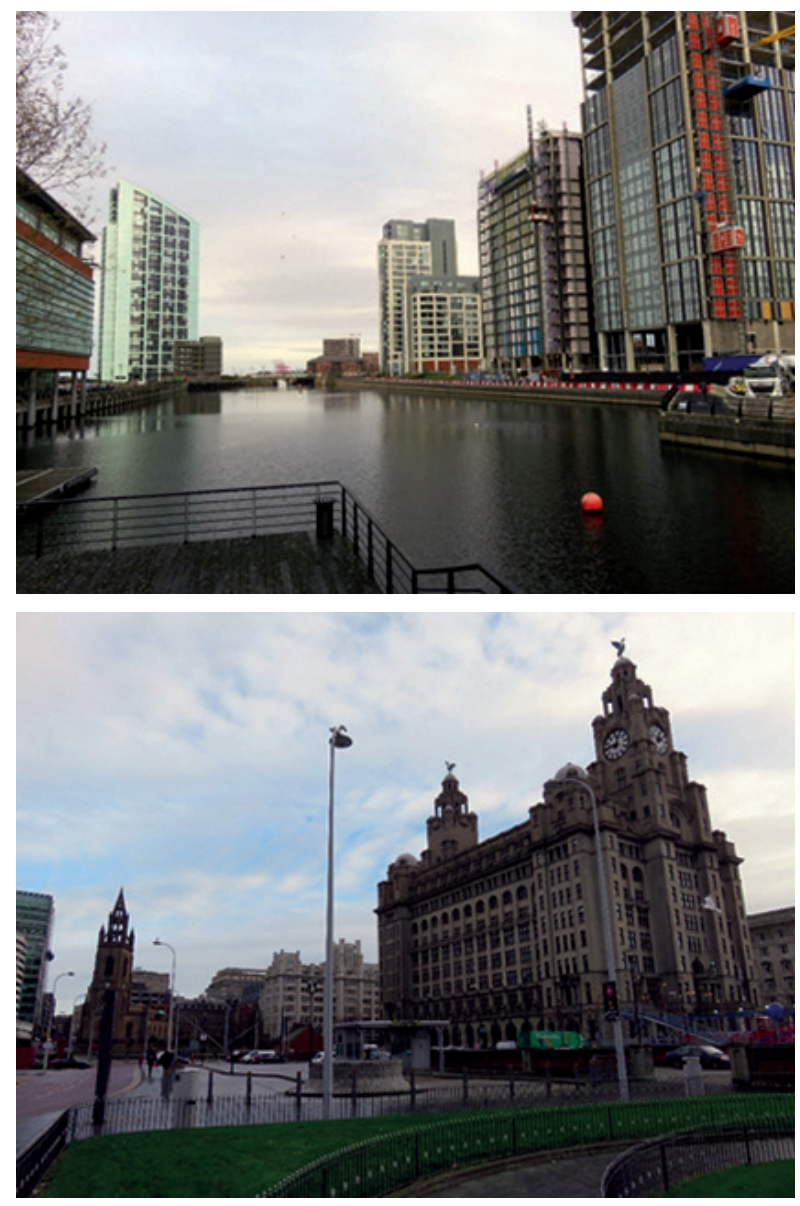

$>$ Figura 6. Princess Dock, Liverpool, Inglaterra. Fuente: Fotografía del autor.

> Figura 7. Royal Liver Building, Liverpool's Pier Head, UK. Fuente: Fotografía del autor. 
haya pervertido. Repito, la cuestión no es dar más importancia a la transmisión que a la conservación, sino un tratamiento igualitario a todos los principios.

También corresponde declarar una última cuestión: soy consciente de dar una visión desde Europa sobre un tema como el Patrimonio Mundial que tiene una visión muy eurocéntrica y creo que eso también influye sobre qué se entiende y cómo se están gestionando al día de hoy los sitios Patrimonio Mundial.

\section{BIBLIOGRAFIA}

\section{General}

Alonso Ibáñez, M. R. (1992) El patrimonio histórico. Destino público y valor cultural. Madrid: Civitas.

Choay, F. (1992) Alegoría del patrimonio. Barcelona: Gustavo Gili, 2007.

Giovine, M. A. di (2009) The heritage-scape. UNESCO, World Heritage, and tourism. Plymouth: Lexington Books.

González-Varas, I. (1999) Conservación de bienes culturales. Teoría, historia, principios y normas. Madrid: Cátedra, 2008.

Lefebvre, H. (1970) La revolución urbana. Madrid: Alianza, 1972.

Lowenthal, D. (1985) El pasado es un país extraño. Madrid: Akal, 1998.

Prats, L. (1997) Antropología y patrimonio. Barcelona: Ariel.

Smith, L. (2006) Uses of heritage. Nueva York: Routledge.

Zukin, S. (1995) The culture of cities. Oxford: Blackwell.

\section{Específica de estudios de caso}

Cox, T. \& O'Brien, D. (2012) The "scouse wedding" and other myths: reflections on the evolution of a "Liverpool model" for culture-led urban regeneration, Cultural Trends, 21:2, 93-101. DOI 10.1080/09548963.2012.674749

Díaz Parra, I. \& Jover, J. (2021) Overtourism, place alienation and the right to the city: insights from the historic centre of Seville, Spain. Journal of Sustainable Tourism, 29: 2-3, 158-175. DOI 10.1080/09669582.2020.1717504

Jover, J. \& Rosa, B. (2017) Patrimonio cultural en disputa: la Mezquita-Catedral de Córdoba. Cuadernos Geográficos, 56: 1, 322-343.

Jover, J., Berraquero Díaz, L., Barrero Rescalvo, M. \& Jiménez Talavera, A. (2018) Turistización y movimientos urbanos de resistencia: experiencias desde Sevilla. En C. Milano \& J. Mansilla (eds.), Ciudad de vacaciones (pp. 403-437). Barcelona: Pol.len.

Lamprakos, M. (2018) Arquitectura, memoria y futuro. La Mezquita-Catedral de Córdoba. Quintana, 17, 43-74.

Rodwell, D. (2014) Negative impacts of World Heritage branding: Liverpool-an unfolding tragedy? Primitive tider special edition, 19-34.

Romero Moragas, C.; Jover Báez, J.; Berdonces Machío, L.; Navarro Mezquita, C.; Gómez Blázquez, D. \& Galera Navarro, V. (2015) Ciudadanía contra el rascacielos Pelli-Cajasol en Sevilla. En: Actas del II Congreso Internacional de Buenas
Prácticas en Patrimonio Mundial: Personas y Comunidades (pp. 481-507). Menorca: Universidad Complutense de Madrid.

\section{Sitios internet}

Sevilla cuando hablo de los nuevos desarrollos en altura https:// www.flickr.com/photos/jaimejover/20473082710/

El Alcázar es uno de los bienes de Sevilla https://www.flickr. com/photos/jaimejover/46634158461/

Sobre el centro histórico de Córdoba https://www.flickr.com/photos/jaimejover/24023154036/

Sobre la zona UNESCO y los nuevos desarrollos en Liverpool https://www.flickr.com/photos/jaimejover/49925833011 